\title{
Competence Based Training (CBT) Teknik Pengelasan Untuk Meningkatkan Keterampilan Taruna Teknika Kapal Niaga
}

\author{
Prasetya Sigit Santosa, Ningrum Astriawati, Waris Wibowo, Wegig Pratama
}

Program Studi Permesinan Kapal, Sekolah Tinggi Maritim Yogyakarta, Jl. Magelang KM 4.4, Kutu Dukuh, Sinduadi, Kec. Mlati, Kabupaten Sleman, Daerah Istimewa Yogyakarta

E-mail: astriamath@gmail.com

\begin{abstract}
Abstrak - Tingginya tuntutan kompetensi di dunia kerja industri pelayaran saat ini menuntut peningkatan keterampilan para Taruna Prodi Teknika Kapal Niaga khususnya pada bidang teknik pengelasan. Hal ini diindikasikan bahwa keterampilan teknik pengelasan Taruna masih rendah. Kegiatan Pengabdian Kepada Masyarakat (PKM) ini bertujuan untuk meningkatkan keterampilan teknik pengelasan dan pemahaman pengelasan bagi taruna. Metode PKM menggunakan Model Competence-Based Training (CBT) yaitu penggabungan teori, demontrasi, dan praktikum. Evaluasi dilakukan dengan melakukan pre-test dan post-test. Peserta CBT adalah taruna kelas 11 SMK Pelayaran Muhammadiyah 1 Kalasan Yogyakarta, bidang keahlian Teknika Kapal Niaga, dengan jumlah 25 taruna. Hasil evaluasi dari Pengabdian Kepada Masyarakat adalah terjadi peningkatan sebesar $60 \%$ penguasaan teori, peningkatan sebesar $64 \%$ terhadap pemahaman demonstrasi dan peningkatan sebesar $84 \%$ terhadap keterampilan taruna dalam melakukan praktik pengelasan.
\end{abstract}

Kata Kunci - Competence Based Training, Keterampilan, Teknik Pengelasan

Abstract - The high demand for competence in the world of the shipping industry today demands an increase in the skills of the Commercial Ship Engineering Study Program cadets, especially in the field of welding techniques. This indicates that Taruna's welding technique skills are still low. This Community Service Activity aims to improve welding technique skills and welding understanding for cadets. The Community Service Activity method uses the Competence-Based Training (CBT) Model, which combines theory, demonstration, and practicum. Evaluation is done by doing a pre-test, and post-test. CBT participants are $11^{\text {th }}$ grade cadets of SMK Pelayaran Muhammadiyah 1 Kalasan Yogyakarta, with the expertise of Commercial Ship Engineering, with a total of 25 cadets. The results of the evaluation of Community Service were an increase of $60 \%$ in theory mastery, an increase of $64 \%$ in understanding demonstrations, and an increase of $84 \%$ in the skills of cadets in welding practice.

Keywords - Competence Based Training, Skills, Welding Techniques

\section{PENDAHULUAN}

Perkembangan teknologi yang makin masif memberikan pengaruh yang besar terhadap kemajuan dunia pendidikan dalam mendidik generasi native digital. Hal ini seiring dengan tuntutan dunia kerja yang akan mensyaratkan tenaga kerja untuk memiliki kecakapan serta keunggulan kompetensi dibidangnya masing-masing[1]. Pencapaian kompetensi yang baik ditentukan dari kualitas proses pendidikan yang dilaksanakan secara efektif dan efisien [2].

Sekolah Menengah Kejuruan (SMK) Pelayaran Muhammadiyah 1 Kalasan merupakan pendidikan kejuruan yang menyiapkan lulusannya siap kerja dalam bidang industri, khususnya industri pelayaran. SMK Pelayaran Muhammadiyah 1 Kalasan memberikan bekal kecakapan hidup kepada peserta didik sesuai dengan kompetensi keahlian, khususnya keahlian Teknika Kapal Niaga. Dalam membentuk kompetensi taruna diperlukan penguasaan teori, pemahaman suatu proses melalui demonstrasi, dan diakhiri dengan kegiatan praktik. Ketiga proses tersebut identik dengan metode pembelajaran Competence Based Training (CBT) yang merupakan suatu pelatihan yang di dalamnya menyajikan pengetahuan, skill dan nilai peserta didik dalam mengembangkan keahlian dan keterampilan[3, 4].

Berdasarkan pengamatan awal taruna belum memiliki keterampilan teknik pengelasan yang baik, sehingga dibutuhkan pelatihan yang sesuai kebutuhan kompetensi. Sekolah Tinggi Maritim Yogyakarta memiliki tenaga pengajar yang telah menguasai keterampilan dan pengetahuan teknik pengelasan serta proses pembelajaran dengan mengembangkan metode Competence Based Training (CBT). Model pembelajaran Competence Based Training (CBT) diyakini dapat memberikan bekal keterampilan dan pengetahuan kepada taruna, dalam kegiatan pengabdian kepada masyarakat ini. Kompetensi taruna ini 
diharapkan mampu bersaing di dunia kerja industri pelayaran.

\section{ANALISIS SITUASI}

Mitra dalam kegiatan PKM ini adalah SMK Pelayaran Muhammadiyah 1 Kalasan Yogyakarta. Kegiatan PKM diawali dengan melakukan observasi, interview, dan diskusi dengan mitra terkait dengan berbagai permasalahan yang dihadapi mitra diantaranya meliputi: (1) kurangnya skill/ keterampilan taruna dalam teknik pengelasan, (2) kebutuhan tenaga ahli tamu dalam peningkatan kompetensi taruna, dan (3) masih kurangnya implementasi kerjasama dalam proses pendidikan taruna.

Permasalahan mitra esensinya sama bahwa masih lemahnya dalam pembentukan kompetensi taruna khususnya teknik pengelasan. Sekolah Tinggi Maritim Yogyakarta melalui program PKM dapat membantu menyelesaikan permasalahan tersebut. Kegiatan yang diusulkan adalah pelatihan untuk meningkatkan skill/ kemampuan taruna dengan model pembelajaran Competence Based Training (CBT).

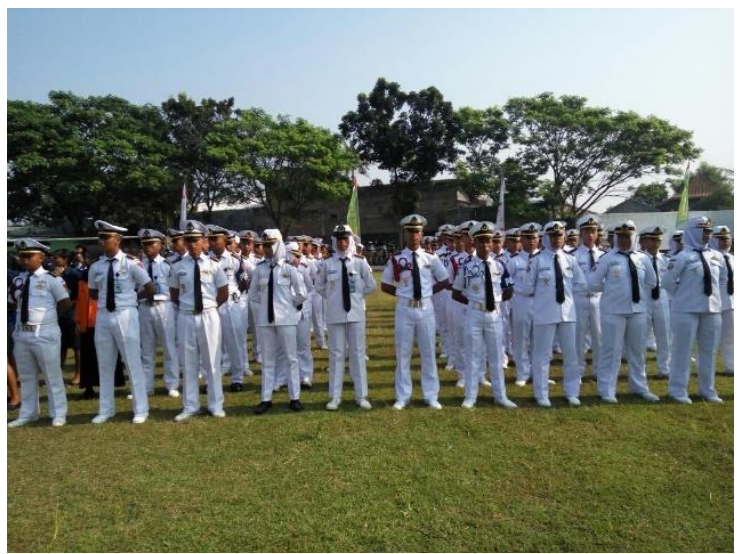

Gambar 1. Taruna/Taruni SMK Pelayaran Muhammadiyah 1 Kalasan Yogyakarta

\section{METODE}

PKM dilaksanakan melalui model pembelajaran Competence Based Training (CBT) menekankan pada 3 (tiga) hal: (1) penguasaan teori, (2) pemahaman melalui demonstrasi, dan (3) praktik. Kegiatan diawali dengan pre-test untuk mengukur kemampuan keterampilan teknik pengelasan taruna. Selanjutnya dilaksanakan pelatihan dengan model pembelajaran CBT. Peserta pelatihan sejumlah 25 taruna kelas 11 bidang keahlian Teknika Kapal Niaga. Proses pembelajaran menggunakan ruang kelas dan laboratorium perbengkelan kapal. Peralatan yang digunakan meliputi: mesin las, kawat las, engine catting, mesin bor, dan gerinda tangan. Proses persiapan pembelajaran Competence Based Training (CBT) meliputi:

a. Ruang kelas b. Peralatan demonstrasi

c. Bahan untuk praktikum

d. Mengecek peralatan las listrik yang tersedia di Laboratorium Perbengkelan Kapal

e. Memberikan pengarahan tentang jobsheet yang akan dikerjakan

f. Memberikan pengarahan tentang menjaga keselamatan dalam praktikum di ruang

laboratorium Pengukuran peningkatan keterampilan dan pemahaman dilaksanakan melalui evaluasi dengan pemberian post-test pada taruna dengan kasus yang sama saat dilaksanakan pre-test[5]. Evaluasi dilakukan dengan pengamatan secara langsung baik didalam kelas mapupun di Laboratorium Perbengkelan Kapal dengan memperhatikan keterampilan peserta CBT satu persatu. Luaran yang diharapkan dari kegiatan PKM ini adalah peningkatan keterampilan teknik pengelasan dan pemahaman pengelasan bagi taruna khususnya taruna Teknika Kapal Niaga.

\section{HASIL DAN PEMBAHASAN}

Kegiatan awal dari kegiatan Pengabdian Kepada Masyarakat ini adalah penjelasan materi mengenai teori teknik pengelasan yang sebelumnya sudah dilakukan pre-test terhadap kemampuan awal tentang penguasaan teori pengelasan. Kegiatan ini dilakukan di dalam kelas. Dalam kegiatan ini dijelaskan mengenai pengertian las busur listrik, klasifikasi las busur listrik, prinsip las busur listrik, parameter pengelasan, kecepatan pengelasan, dan teknik-teknik pengelasan yang baik. Akhir dari kegiatan ini adalah dilakukan post-test untuk mengukur tingkat pemahaman secara teori mengenai teknik pengelasan.

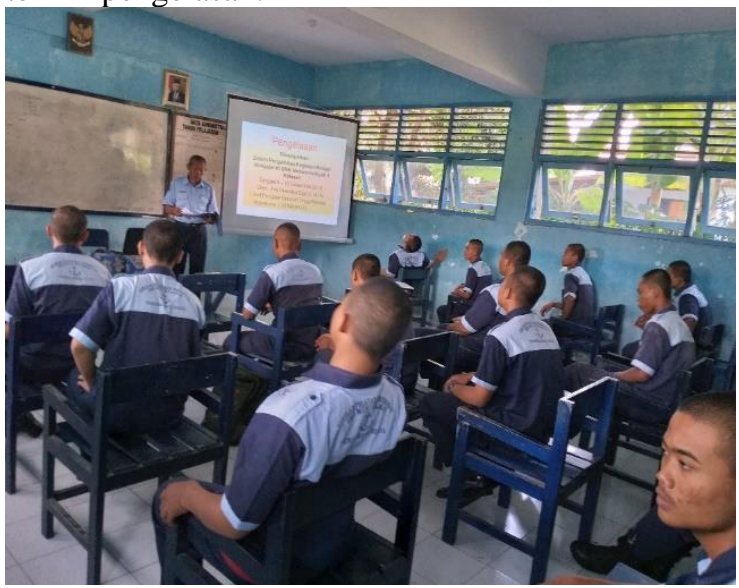

Gambar 2. Penjelasan secara teori di kelas tentang teknik pengelasan

Kegiatan selanjutnya adalah melakukan demonstrasi. Dalam melakukan demonstrasi teknik pengelasan yang harus diperhatikan/ diajarkan dalam mengelas adalah memahami jobsheet atau lembar kerja yang akan dilakukan pengelasan, logam yang akan dilas harus disesuaiakan dengan kawat las. Dalam proses pengelasan yang harus diperhatikan adalah pengaturan arus. Di dalam demonstrasi juga dilakukan pre-test dan 
post-test untuk mengukur pemahaman teknik pengelasan taruna. Satu instruktur memberikan contoh teknik pengelasan, sedangkan instruktur lain mengamati secara langsung mengenai pemahaman taruna. Gambar berikut merupakan metode demonstrasi yang diberikan kepada taruna peserta pelatihan.

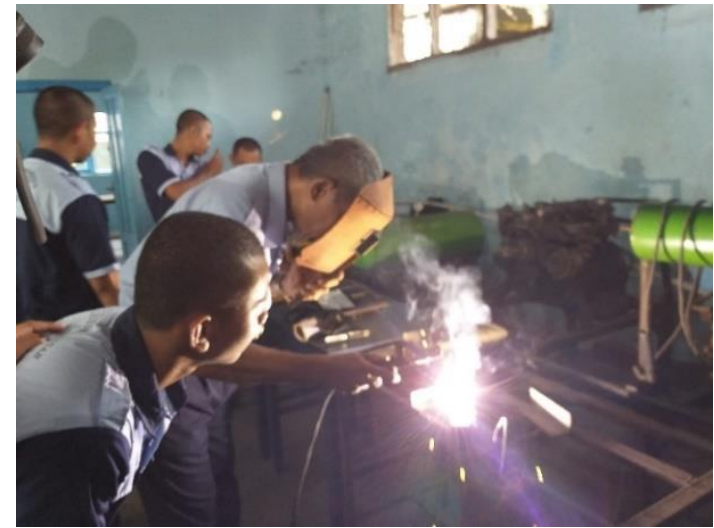

Gambar 3. Metode demonstrasi cara pengelasan menggunakan las listrik

Kegiatan selanjutnya adalah dengan metode praktik. Dalam metode ini taruna melakukan praktik langsung seperti yang sudah diajarkan oleh instruktur. Di dalam metode ini juga dilakukan pretest dan post-test dengan tujuan untuk mengukur peningkatan keterampilan taruna dalam teknik pengelasan dan sambungannya. Gambar berikut merupakan metode praktik yang dilakukan oleh taruna.

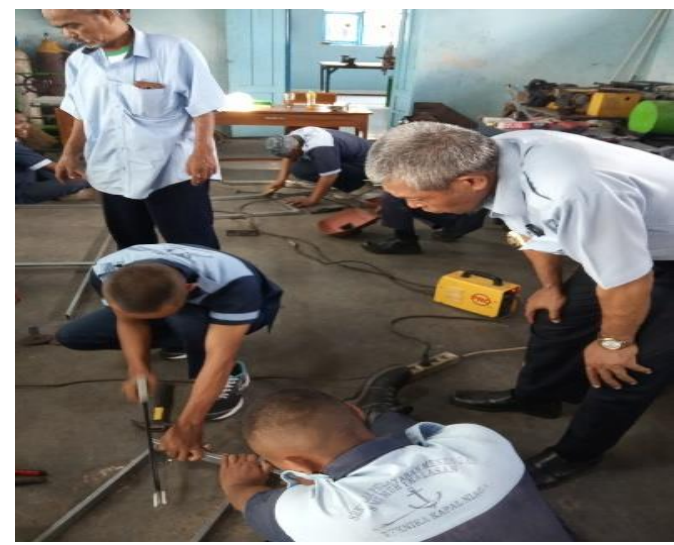

Gambar 4. Taruna praktik dengan metode sambungan permanen menggunakan las listrik

Dari hasil pelaksanaan Competence Based Training (CBT) teknik pengelasan untuk Taruna Teknika Kapal Niaga diperoleh bahwa untuk penguasaan teori terjadi peningkatan sebesar $60 \%$ hal ini ditandai dari hasil persentase pre-test sebesar $32 \%$ dan post-test sebesar 92\%. Pemahaman demonstrasi terjadi peningkatan $64 \%$, hal ini ditandai dengan hasil persentase pre-test sebesar
$24 \%$ dan post-test sebesar $88 \%$. Persentase yang paling besar kenaikannya adalah pada keterampilan taruna dalam melakukan praktik yaitu terjadi peningkatan sebesar $84 \%$, hal ini ditandai dari hasil persentase pretest sebesar $12 \%$ dan post-test sebesar $96 \%$. Secara keseluruhan evaluasi yang diperoleh dalam pengelasan taruna SMK Pelayaran Muhamadiyah 1 antara lain : (1) Masih ada beberapa taruna saat mengelas jarak elektroda terlalu dekat dengan bahan yang dilas, sehingga elektroda menempel pada bahan las, (2) Dari beberapa jobsheet yang diberikan rata-rata taruna dapat mengerjakan pengelasan dengan baik.

Tabel 1. Hasil pre-test dan post-test pelaksanaan Competence Based

\begin{tabular}{cccccc}
\multicolumn{6}{c}{ Training (CBT) } \\
\hline No & $\begin{array}{c}\text { Metode } \\
\text { Penilaian }\end{array}$ & $\begin{array}{c}\text { Jumlah } \\
\text { pretest }\end{array}$ & $\begin{array}{c}\text { Persen } \\
\text { Pretest }\end{array}$ & $\begin{array}{c}\text { Jumlah } \\
\text { posttest }\end{array}$ & $\begin{array}{c}\text { Persen } \\
\text { posttest }\end{array}$ \\
\hline 1 & $\begin{array}{l}\text { Penguasaan } \\
\text { teori }\end{array}$ & 8 & $32 \%$ & 23 & $92 \%$ \\
2 & $\begin{array}{l}\text { Pemahaman } \\
\text { demonstrasi }\end{array}$ & 6 & $24 \%$ & 22 & $88 \%$ \\
3 & $\begin{array}{l}\text { Keterampilan } \\
\text { praktik }\end{array}$ & 3 & $12 \%$ & 24 & $96 \%$ \\
\hline
\end{tabular}

\section{KESIMPULAN}

Kegiatan Pengabdian Kepada Masyarakat yang dilakukan oleh Prodi Permesinan Kapal Sekolah Tinggi Maritim Yogyakarta melalui model pembelajaran Competence Based Training (CBT) menekankan pada 3 (tiga) hal: (1) penguasaan teori, (2) pemahaman melalui demonstrasi, dan (3) praktik. Dari hasil pelaksanaan CBT teknik pengelasan untuk Taruna Teknika Kapal Niaga diperoleh bahwa untuk penguasaan teori terjadi peningkatan sebesar $60 \%$, pemahaman demonstrasi terjadi peningkatan $64 \%$, keterampilan taruna dalam melakukan praktik yaitu terjadi peningkatan sebesar $84 \%$. Secara keseluruhan terjadi peningkatan dalam model pembelajaran CBT yang dilakukan pada Taruna Teknika Kapal Niaga di SMK Pelayaran Muhammadiyah 1 Kalasan Yogyakarta baik dalam segi peningkatan keterampilan teknik pengelasan dan pemahaman pengelasan.

\section{UCAPAN TERIMA KASIH}

Pengabdian Kepada Masyarakat ini didanai oleh Lembaga Penelitian dan Pengabdian kepada Masyarakat Yogyakarta Sekolah Tinggi Maritim pada tahun 2019. Kami berterima kasih kepada Kepala Sekolah dan guru-guru SMK Pelayaran Muhamadiyah 1 yang telah memberikan bantuan dan dukungan pada kegiatan PKM ini.

\section{DAFTAR PUSTAKA}

[1] H. Wasiati and D. Wijayanti, "Sistem Pendukung Keputusan Penentuan Kelayakan Calon Tenaga Kerja Indonesia Menggunakan Metode Naive Bayes (Studi Kasus: Di P.T. Karyatama Mitra Sejati Yogyakarta)," IJNS Indones. J. Netw. Secur., 2014. 
Jati Emas (Jurnal Aplikasi Teknik dan Pengabdian Masyarakat)

[2] F. Fakhrurrazi, "Hakikat Pembelajaran Yang Efektif," At-Tafkir, 2018, doi: 10.32505/at.v11i1.529.

[3] S. Paryanto, "Model Pembelajaran Competence Based Training (Cbt) Berbasis Karakter Untuk Pembelajaran Praktik Kerja Mesin Di Sekolah Menengah Kejuruan," $J$. Pendidik. Karakter, vol. IV, no. 3, pp. 281293, 2014.
[4] M. N. Malik, S. Soenarto, and F. Sudarsono, "The competency-based training model for vocational high school teachers from electrical expertise programs," J. Pendidik. Vokasi, 2018, doi: 10.21831/jpv.v8i3.19877.

[5] E. Marsden and C. J. Torgerson, "Single group, pre- and post-test research designs: Some methodological concerns," Oxford Rev. Educ., 2012, doi: 10.1080/03054985.2012.731208. 